\title{
Interventions for supporting nurse retention in rural and remote areas: an umbrella review
}

\author{
Gisèle Mbemba', Marie-Pierre Gagnon ${ }^{1 *}$, Guy Paré and José Côté ${ }^{3}$
}

\begin{abstract}
Context: Retention of nursing staff is a growing concern in many countries, especially in rural, remote or isolated regions, where it has major consequences on the accessibility of health services.

Purpose: This umbrella review aims to synthesize the current evidence on the effectiveness of interventions to promote nurse retention in rural or remote areas, and to present a taxonomy of potential strategies to improve nurse retention in those regions.

Methods: We conducted an overview of systematic reviews, including the following steps: exploring scientific literature through predetermined criteria and extracting relevant information by two independents reviewers. We used the PRISMA (Preferred Reporting Items for Systematic reviews and Meta-Analyses) criteria in order to assess the quality of the reports.

Findings: Of 517 screened publications, we included five reviews. Two reviews showed that financial-incentive programs have substantial evidence to improve the distribution of human resources for health. The other three reviews highlighted supportive relationships in nursing, information and communication technologies support and rural health career pathways as factors influencing nurse retention in rural and remote areas. Overall, the quality of the reviews was acceptable.

Conclusions: This overview provides a guide to orient future rural and remote nurse retention interventions. We distinguish four broad types of interventions: education and continuous professional development interventions, regulatory interventions, financial incentives, and personal and professional support. More knowledge is needed regarding the effectiveness of specific strategies to address the factors known to contribute to nurse retention in rural and remote areas. In order to ensure knowledge translation, retention strategies should be rigorously evaluated using appropriate designs.
\end{abstract}

Keywords: Nurse shortage, Nurse retention, Rural retention, Rural health services, Umbrella review

\section{Introduction}

Understanding nursing shortage on a global scale is a complex matter. The definition or measure of nurse shortage $[1,2]$ or the establishment of the right ratio of nurses to population [1] may vary between countries and make statistical comparisons harder. However, as Buchan and Aiken pointed out, nursing shortage "is not just about number, but about how the health system functions to enable nurses to use their skills effectively"

\footnotetext{
* Correspondence: marie-pierre.gagnon@fsi.ulaval.ca

'Hôpital St-François d'Assise, Research Center of the Centre Hospitalier Universitaire de Québec, 10 rue de l'Espinay, D6-727, G1L 3L5, Québec, QC, Canada

Full list of author information is available at the end of the article
}

[1]. When nursing shortage occurs, on the local or global scale, it may lead, if not addressed, to the failure of healthcare [1].

Acute nursing shortage is a growing concern in developing and developed countries [1,2]. In a survey among 70 members states of the World Health Organization (WHO), nursing shortage was experienced by $86 \%$ of them and, in $54 \%$ of these countries, nursing shortage was of a great intensity [3]. In a developed country such as Canada, recruiting and retaining nurses is becoming a main challenge for decision makers [4] in the light of the predicted nursing shortage and its concomitant effects on healthcare [5]. There is a current shortfall of

\section{Biomed Central}

(C) 2013 Mbemba et al.; licensee BioMed Central Ltd. This is an Open Access article distributed under the terms of the Creative Commons Attribution License (http://creativecommons.org/licenses/by/2.0), which permits unrestricted use, distribution, and reproduction in any medium, provided the original work is properly cited. 
22,000 nurses, and a shortfall of 60,000 full-time equivalent nurses is expected by 2022 [6].

The literature mentions close ties between nursing shortage and geographical imbalances in nursing $[7,8]$ or the health workforce [9-12]. Some studies focus on international nurse migration and the 'brain drain' from developing to developed countries [2]. Other studies stress the remote, rural and underserved areas where nursing shortage is more acute [13], both in developing $[8,14]$ and developed countries $[7,15]$.

Rural and remote areas have more difficulties in recruiting and retaining nurses when compared to the greater career opportunities and work prospects in urban areas $[1,7,12]$. Additional barriers to recruitment and retention of healthcare staff in remote areas are poor working conditions $[9,16]$, professional isolation [17], lack of services in the general living environment [16], and higher mobility of health professionals associated with globalization [9]. Insufficient numbers and loss of nurses and the health workforce impede rural and remote populations to obtain healthcare services. As reported by the WHO, only $38 \%$ of the nursing workforce remains in rural areas, where almost half of the world's population lives [13].

The evidence about the effectiveness of rural retention interventions comes mostly from advanced economies like Australia, Canada or the USA [10]. Among studies of nurse or health worker retention in remote areas from developed countries, the rural background $[7,10,15,18]$ or the rural integration $[18,19]$ may constitute a powerful predictor of rural practice. These personal and social factors are interconnected with others that influence the decision of nurses or health workers to stay in or leave rural and remote areas: financial aspects, career aspirations, working and living conditions and bounding or mandatory service $[11,13]$. In order to have a better understanding of the factors influencing the retention of health staff, the WHO has elaborated a model of heath workers' decision to relocate, stay, or leave rural and remote areas that proposes four categories of interventions to improve their retention in these settings: education, regulation, financial incentives, and personal and professional support [13].

The objective of this review is to synthesize the current scientific evidence on interventions to promote nurse retention in rural, peripheral or remote areas, and to present a taxonomy of potential strategies in order to propose further research directions. The rest of this paper is organized as follows: the first section outlines the research methodology used for this review; the second section presents the results of research about interventions for supporting nurse retention in rural and remote areas; and the third section proposes a taxonomy of nurse retention strategies, based on the WHO model, as well as potential future research propositions.

\section{Methods}

We performed a systematic review of prior reviews, a method also known as umbrella review [20-22], to synthesize the scientific evidence regarding interventions that support nurse retention in rural, peripheral or remote areas. We used the following keywords, and their variations, in combination with each other: nurse shortage, nurse retention, rural retention, systematic review or literature review. We consulted the following databases: MEDLINE (PubMed interface), CINAHL, EMBASE and the search engine Google Scholar. While the search was international, we limited inclusion of publications from a 22-year period (January 11990 to July 31 2012). The included studies met the following inclusion criteria: (i) derived from a systematic review; (ii) involved nursing professionals; (iii) assessed factors that influenced retention in rural or remote areas; and (iv) were published in English, French, or Spanish. We excluded studies that were not reviews, did not involve nurses, did not specifically concern rural and remote areas, and were published in other languages.

The systematic review process is shown in Figure 1. First, two members of the research team (GM and MPG) independently read the title and abstract of each retrieved article to identify potentially relevant reviews. Then, the same two persons independently reviewed the full text of each potentially relevant article, compared their results and agreed about the final codification. Finally, we used the Preferred Reporting Items for Systematic reviews and Meta-Analyses (PRISMA) criteria for reporting systematic reviews and meta-analyses of studies that evaluate healthcare interventions, a quality appraisal tool developed by Liberati and colleagues [23]. This evaluation of the quality of reporting did not aim to decide study inclusion or exclusion, but rather to consider this score in the interpretation of our results.

\section{Results}

From an initial pool of 517 publications, we selected a total of five review articles that met the inclusion criteria [24-28].

Table 1 presents the five reviews of nurse retention interventions in rural and remote areas that were selected. The first one examined the effects of financial incentives for return of service in underserved areas [24]. The second synthesized the available evidence regarding the effectiveness of retention strategies for health workers in rural and remote areas [25]. The third review defined the three main supportive relationships identified in the nursing literature [26]. The fourth one explored the impact of interventions using information and communication technologies (ICTs) on recruitment and retention of healthcare professionals in less-served regions [27], while the fifth review described stages related to recruitment 


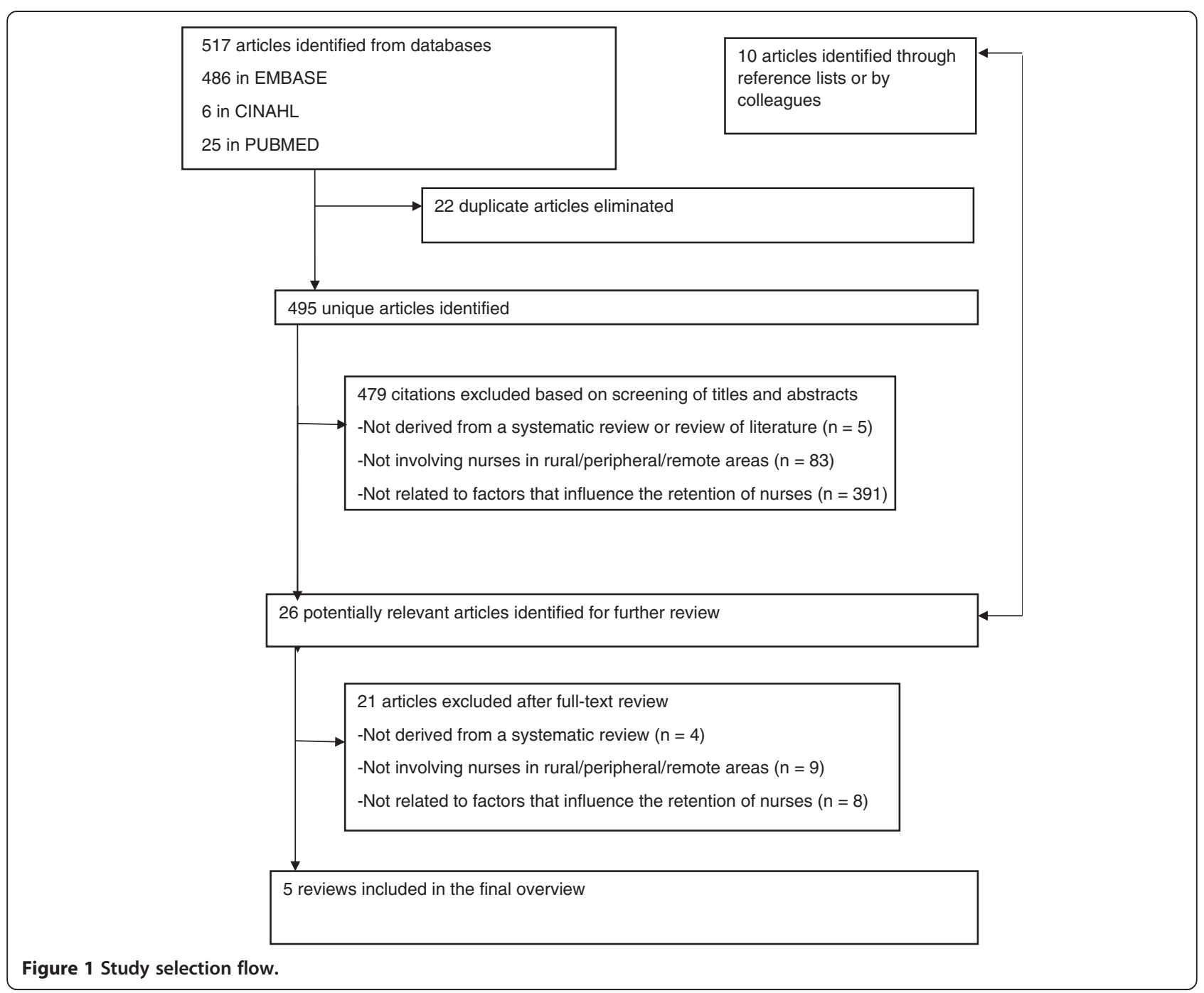

and retention of health professionals to rural health careers [28]. As shown in Table 1, three of the reviews $[24,25,27]$ met more than $66 \%$ of the PRISMA appraisal criteria while the other two $[26,28]$ met more than $50 \%$ of them.

From the profile of the reviews included in this study, we have classified interventions into four different themes: financial incentives, supportive relationships in nursing, ICT support, and career pathways for rural health.

\section{Financial incentives}

The review by Bärnighausen and Bloom [24] synthesized 43 empirical studies, 34 of which investigated financial incentives in the USA. The remaining studies evaluated programs in Japan (five studies), Canada (two), New Zealand (one) and South Africa (one). The review identified five different types of financial-incentive programs for return of service: service requiring scholarships, educational loans with service requirements, serviceoption educational loans, loan repayment programs, and direct financial incentives. Direct financial incentives are usually provided at the entry into practice in an underserved area and the money from this type of program can be used for different purposes, whereas loan repayments are provided after each period of service, and the money must be spent on healthcare education. Studies included in the review by Bärnighausen and Bloom [24] contributed to several outcomes such as: 1) program outcomes among participants which encompass recruitment (14 studies), retention (17 studies), participant satisfaction (7 studies), and family satisfaction (3 studies); 2) program effectiveness at the individual level with outcomes on provision of care (11 studies), retention (7 studies), and participant satisfaction (2 studies); 3) program effectiveness at the population level with outcomes on health system (6 studies), and health outcomes (for example, mortality) (1 study). The number of studies in 


\section{Table 1 Profile of the reviews considered in this overview}

\begin{tabular}{|c|c|c|c|c|c|c|c|}
\hline Title & Authors & $\begin{array}{l}\text { Year of } \\
\text { publication }\end{array}$ & Country & $\begin{array}{l}\text { Number of } \\
\text { included studies }\end{array}$ & $\begin{array}{l}\text { Type of } \\
\text { professionals }\end{array}$ & Study variables & $\begin{array}{l}\text { PRISMA } \\
\text { score }\end{array}$ \\
\hline $\begin{array}{l}\text { Financial incentives for return of service in underserved areas: } \\
\text { a systematic review }\end{array}$ & $\begin{array}{l}\text { Bärnighausen and } \\
\text { Bloom [24] }\end{array}$ & 2009 & USA & 43 & Nurses and physicians & Financial incentives & $22 / 27$ \\
\hline $\begin{array}{l}\text { Systematic review of effective retention incentives for health } \\
\text { workers in rural and remote areas: towards evidence-based policy }\end{array}$ & Buykx et al. [25] & 2010 & Australia & 14 & Nurses and physicians & $\begin{array}{l}\text { Retention strategies (financial } \\
\text { incentives, loan repayment) }\end{array}$ & $19 / 27$ \\
\hline $\begin{array}{l}\text { Mentoring, clinical supervision and preceptoring: clarifying the } \\
\text { conceptual definitions for Australian rural nurses: a review of } \\
\text { the literature }\end{array}$ & Mills et al. [26] & 2005 & Australia & Not specified & Nurses & $\begin{array}{l}\text { Supportive relationships in } \\
\text { nursing: mentoring, clinical } \\
\text { supervision and preceptoring }\end{array}$ & $17 / 27$ \\
\hline $\begin{array}{l}\text { Supporting health professionals through information and } \\
\text { communication technologies: a systematic review of the } \\
\text { effects of information and communication technologies on } \\
\text { recruitment and retention }\end{array}$ & Gagnon et al. [27] & 2011 & Canada & 13 & $\begin{array}{l}\text { Nurses and other care } \\
\text { providers }\end{array}$ & ICTs support & $21 / 27$ \\
\hline $\begin{array}{l}\text { Rural health career pathways: research themes in recruitment } \\
\text { and retention }\end{array}$ & Fisher and Fraser [28] & 2010 & Australia & Not specified & $\begin{array}{l}\text { Nurses and other } \\
\text { providers }\end{array}$ & Stages of rural career pathways & $17 / 27$ \\
\hline
\end{tabular}

ICTs information and communication technologies, PRISMA Preferred Reporting Items for Systematic reviews and Meta-Analyses. 
parentheses adds up to 68 , because some studies contribute two or three outcomes each.

Globally, this systematic review found substantial evidence of the effectiveness of financial-incentive programs for return of service as a health policy intervention to attract human health resources in underserved areas. Evidence on the impact of financial incentives was, however, limited regarding retention in rural areas. Limitations of this review include the fact that a majority of included studies were from the USA and only one study took place in a low-resource country (South Africa). Furthermore, the number of studies that included nurses is not provided. The results from this review show that financial-incentive programs placed substantial numbers of health workers in underserved areas and that program participants were more likely than non-participants to work in underserved areas in the long run, even though they were less likely to remain at their site of original placement. In terms of quality of reporting, the review met more than $66 \%$ of the PRISMA criteria.

Next, the systematic review by Buykx and colleagues synthesized the effectiveness of retention strategies for health workers in rural and remote areas [25]. However, this review of 14 papers found only one study on the effectiveness of nurse retention strategy. Six studies focused on medical practitioners, five were about healthcare professionals in general but with strong emphasis on medical doctors, and one focused on psychiatrists.

Financial incentives were the most commonly reported retention strategies. This systematic review provides limited support to the effectiveness of financial incentive interventions, suggesting that financial incentives are more effective to improve recruitment and short-term retention of healthcare workers than for fostering their long-term retention in underserved areas. Strategies in which health workers have some form of obligation (such as visa conditions restricting area of practice or loan repayment) could be more effective in retaining them on a longer period. However, there is some evidence that indicates that non-financial incentives, such as providing quality working and housing conditions, could have more impact on the decision of healthcare workers to stay in the area.

\section{Supportive relationships in nursing}

The review by Mills and colleagues [26] examined the three main supportive relationships identified in the nursing literature that affect retention and recruitment: mentoring, clinical supervision and preceptoring. This review aimed to highlight the similarities and differences among them and to illuminate the range of possible supportive relationships that could be fostered by decisionmakers. Each of these three types of coaching will be examined in turn.

\section{Mentoring}

According to Steward and Krueger [29], the definition that most adequately reflects the concept of mentoring in nursing today is "Mentoring in nursing is a teachinglearning process acquired through personal experience within a one-to-one, reciprocal, career development relationship between two individuals diverse in age, personality, life cycle, professional status, and/or credentials" (page 315).

This systematic review [26] identified very few studies that explicitly focused on rural nurse mentors. One study was from the USA and explored the outcomes of mentoring partnerships arranged between academic mentors and beginner rural nurse practitioners. However, there are formal mentoring programs in Australia that are also mentioned [26]. One of these programs involved undergraduate rural and remote nurses, aged care nurses and re-entry to practice nurses who held Australian government scholarships. This comprehensive evaluation of a mentoring project, initiated by the Association for Australian Rural Nurses, has highlighted the influence of continuing education on rural nurse mentors and the relationships that they form with their mentees [26].

\section{Clinical supervision}

The authors of this review [26] defined clinical supervision as "a support mechanism for practising professionals within which they can share clinical, organisational, development and emotional experiences with another professional in a secure confidential environment in order to enhance knowledge and skills" (page 4). This process will lead to an increased awareness of other concepts including accountability and reflective practice [30]. One-on-one, triad, and group represent three forms of clinical supervision. According to this systematic review [26], group clinical supervision would be particularly effective, especially if conducted off-site, held frequently and of substantial length. Also, the rural nurses felt that their clinical supervision experiences were valuable in improving their understanding about their practice, as well as increasing their selfawareness and ability to critically reflect [31].

\section{Preceptoring}

Unlike mentoring and clinical supervision, preceptoring in nursing involves clinical staff, as opposed to faculty staff, in order to provide supervision and clinical instruction to undergraduate or newly registered nurses, or those new to a specific clinical environment [32]. Usually, preceptoring is conducted on a one-on-one basis. This approach strengthens the relationship between the undergraduate or newly registered nurse and their preceptor to quickly adapt in the workplace. Also, the development of a preceptorship program is a way to bridge 
the gap between nursing education and service [32]. However, the 'clinical teaching associate' is another model of preceptoring where healthcare facilities are funded by university in order to release a clinician, often called the clinical associate, who is responsible for supervising and teaching a small group of students [33].

In conclusion, Australian rural nursing experiences showed that mentoring, clinical supervision, and preceptoring are all valuable in meeting the particular challenge of recruitment and retention of rural nurses. Thus, these strategies seem to be essential when considering policies aiming at ensuring recruitment and retention of rural nurses in the future. One strength of this review is that it focuses only on studies involving nurses. In terms of rigor, the review met more than $50 \%$ of the critical appraisal criteria.

\section{Information and communication technologies support}

In their systematic review, Gagnon and colleagues [27] synthesized 13 studies in order to explore the impact of interventions using ICTs on recruitment and retention of healthcare professionals. Of the 13 studies, five are related to both recruitment and retention. Five other studies exclusively examine retention, whereas the other three pertain only to recruitment. Except for one older study, all other studies target the domain of telehealth. This review showed that ICTs might have positive effects on the recruitment and retention of healthcare professionals in rural and remote regions. For instance, one study showed the influence of telehealth on the decision of surveyed physicians to stay in rural practice [34], and another showed the positive impact of telehealth on nurse retention [35].

However, it seems that the effects of ICTs are more noticeable on the diverse constitutive recruitment and retention factors, such as reduction of professional isolation, networking, decision-making support, improvement of quality of life, and job satisfaction. Although very few studies have investigated this topic, it is estimated that these results can be in part transferable to the situation of nurses who practice in remote areas. In terms of rigor, this review met more than $66 \%$ of the PRISMA quality appraisal criteria.

\section{Career pathways for rural health}

The review by Fisher and Fraser [28] identified four stages of rural career pathways. These authors have consulted the research literature on recruitment and retention to rural health careers (principally in developed regions such as Australia, New Zealand, Europe, the USA and Canada) and propose a framework consisting of four stages that is similar to the 'rural pipeline' of physicians described in the medical literature. In this review, the notion of the pipeline is broadened. It embraces other health professions, especially nursing.

The different stages are described as follows. The first stage, 'making career choices' (structured contact between secondary schools and health professionals), includes promotion of health careers such as medicine, nursing and allied health [36].

The second stage, 'being attached to place' (rural student selection), concerns attraction of rural students. The literature supports the relationship between attachment to the place where the student originates and rural practice, thus favoring the selection of rural students into medical programs in Australia [37]. Moreover, longterm living in a rural community could also contribute to this attachment by increasing social bonds among members of the community [38]. However, information available on the effects of rural student selection in professions such as allied health and nursing remains low.

The third stage, 'taking up rural practice' (rural exposure), acknowledges that exposure to rural clinical settings and different locations can increase interest in rural practice for medical, nursing and allied health students [39]. The authors concluded that rural exposure could indeed increase interest in rural practice, but that cultural issues are essential to consider in the rural nursing profession to improve the nurturing role that supervisors provide to students.

The fourth stage, 'remaining in rural practice' (educational and professional support), is concerned with time spent in a rural context, contentment of rural life and balancing personal and professional roles. Some important factors influencing the retention of rural health professionals are identified; for instance, nurses identified professional support as an important component of retaining nursing staff in rural areas.

Overall, several studies in this systematic review suggest that both personal and work-related factors can impact retention, which requires strategies that address these multiple causes simultaneously. The 'rural pipeline' model could be a useful template for future research because it describes the various phases in the rural practice for which specific interventions may be more effective. Using a common framework would also enhance and consolidate evidence to ensure a coordinated approach to recruitment and retention of all health professionals in rural areas. In terms of rigor, this review scored lower because it lacks information about the number of included studies and the type of health professionals who are targeted in each study.

\section{Taxonomy of nurse retention interventions in rural and remote areas}

In this section, we propose a taxonomy of strategies to increase nurse retention in rural and remote areas. 
These interventions are extracted from the systematic reviews described above. The strength of evidence associated to each intervention is also provided, based on review authors' conclusions regarding the effectiveness of each specific intervention and also on the fact that this evidence concerns nurses (direct evidence) or any healthcare providers (indirect evidence). Table 2 presents the specific interventions assessed in the five included reviews, according to the four broad types of interventions proposed in the WHO model [13]: (i) education and continuous professional development interventions, (ii) regulatory interventions, (iii) financial incentives (direct and indirect), and (iv) personal and professional support.

\section{Education and continuous professional interventions}

Education and continuous professional interventions encompass several activities, such as making career choices. These interventions include promotion of careers such as medicine, nursing and allied health. According to Fisher and Fraser [28], these approaches could overlook some of the socioeconomic barriers that rural students may face when making their career choice. Rural exposure has some positive outcomes in increasing interest in rural practice for medical, nursing and allied health students. Access to educational opportunities is an important factor contributing to nurse retention in remote and rural areas. Although there is a well-developed program of continuing education for medical practitioners, it seems that continuing education programs for other health professionals are less developed. Current evidence suggests that the coordination of a structured support system could strengthen and sustain retention of health professionals in rural areas [40]. However,
ICTs can have an influence on factors related to the recruitment and retention, but the impact of ICTs on nurse retention has received little attention in the scientific literature. Some studies indicate that these technologies could support nurse retention through improved professional development [27].

\section{Regulatory interventions}

Regulatory interventions to support recruitment and retention in rural areas are related to expanding the scope of practice of rural health workers, and developing new categories of health workers. Foreign-recognition of qualifications represents another regulatory measure but it mostly applies to physicians. Also, little evidence is available regarding facilitated entry into universities for rural students in allied health and nursing professions [27].

\section{Financial incentives}

Financial incentives are the only strategies that have been largely evaluated. However, evidence of their effectiveness to support nurse retention in remote and rural areas remains limited as of today. For instance, Buykx and colleagues [25] consider that financial incentives are not very effective for long-term retention.

\section{Personal and professional support}

Personal and professional support creates a supportive relationship for nurses contemplating a shift to the rural environment at the beginning of their employment and may provide an incentive to stay. Evidence from the review by Mills and colleagues [26] indicate that mentoring, clinical supervision and preceptoring are key measures that needs

Table $\mathbf{2}$ Taxonomy of nurse retention interventions in rural and remote areas

\begin{tabular}{|c|c|c|}
\hline Category of intervention & Effective interventions for nurse retention & Strength of evidence ${ }^{*}$ \\
\hline \multirow{4}{*}{$\begin{array}{l}\text { A. Education and continuous professional } \\
\text { development interventions }\end{array}$} & -Recruitment from, and training in, rural areas & Moderate $[26]^{\#}$ \\
\hline & -Targeted admission of students from rural background & Moderate $[28]^{\#}$ \\
\hline & -Early and increased exposure to rural practice during undergraduate studies & \\
\hline & -Support for continuous professional development & \\
\hline \multirow[t]{3}{*}{ B. Regulatory interventions } & -Increased opportunities for recruitment to civil service & Low $[25]^{\#}$ \\
\hline & -Recognizing overseas qualifications & \\
\hline & -Producing different types of health workers & \\
\hline \multirow[t]{2}{*}{ C. Financial incentives } & \multirow{2}{*}{$\begin{array}{l}\text {-Direct and indirect financial incentives (direct payments, service-requiring } \\
\text { scholarships, educational loans with service requirements, loan } \\
\text { repayment programs) }\end{array}$} & Moderate $[24]^{\#}$ \\
\hline & & Low $[25]$ \\
\hline \multirow[t]{3}{*}{ D. Personal and professional support } & $\begin{array}{l}\text {-General improvement in rural infrastructure (housing, roads, phones, water } \\
\text { supplies, radio communication, etc.) }\end{array}$ & Strong $[25]$ \\
\hline & -Supportive supervision (mentorship, preceptorship, clinical supervision) & Moderate $[26]^{\#}$ \\
\hline & $\begin{array}{l}\text {-Measures to reduce health workers' feeling of isolation (professional/specialist } \\
\text { networks, telemedicine and telehealth) }\end{array}$ & Moderate $[27]^{\#}$ \\
\hline
\end{tabular}

"Strength of evidence based on review authors' conclusions.

\#Indirect evidence: the original studies on which authors based their conclusions are not specific to nurse retention. 
to be factored into rural health service planning for undergraduate students contemplating a rural nursing career. For practicing rural nurses, supportive relationships within the workplace represent a pragmatic commitment that entices them to stay.

\section{Discussion and conclusion}

This umbrella review reveals that financial incentives, supportive relationships in nursing (mentoring, clinical, supervision, preceptoring), ICT support and the career pathways for rural health constitute potential strategies that could influence the retention of nurses in rural and remote areas. Even though the impact of financial interventions is supported by two reviews [24,25], most of the studies included in these reviews are from the USA, making the results less applicable to countries with a different healthcare system such as Australia and Canada, or to low- and middle-income countries.

Very few empirical studies explored the impact of supportive relationships in nursing and, thus, the evidence regarding this type of intervention is quite limited. The review on ICT usage found some evidence of its effect on medical professionals; however, there is a lack of literature on other health workers [27]. Although research specific to rural nursing is growing, it is still very limited [41].

This umbrella review aimed to synthesize the main factors that influence nurse retention in rural or remote areas. This synthesis allows us to propose a taxonomy of interventions for rural and remote nurse retention. This taxonomy is based on the categories of the model proposed by the WHO. It is also inspired by the framework proposed by Buykx and colleagues [25]. In order to maximize the use of retention funding for the purpose of minimizing avoidable turnover, Buykx and colleagues [25] suggest using a framework that addresses known determinants of poor retention which could support resource allocation decisions based on scientific evidence. Retention funding should also be seen as an ingredient of a comprehensive retention strategy developed on the basis of local needs. Finally, Buykx and colleagues suggest that the impact of strategies on subsequent workforce retention should be assessed using rigorous evaluation methods [25]. Given the limited empirical evidence available on effective retention strategies for rural and remote nurses, we also encourage more research on the main determinants of nursing retention in rural and remote areas that could inform future strategies.

\section{Limitations}

This umbrella review provides a starting point in order to orient future interventions aiming at increasing nurse retention in rural and remote areas. However, results should be interpreted with caution as we did not look at individual studies included in the five systematic reviews. Thus, our interpretation relies on the judgment of review authors. Also, the average PRISMA score of some reviews mean that the results should be interpreted with caution. Although we tried to include reviews of interventions for nurse retention in rural or remote areas, most of the reviews also included other health providers, highlighting the need for more reviews focusing on retention strategies specific to nursing.

\section{Final remarks/need for further research}

The use of the PRISMA checklist of items for reporting systematic reviews showed that only two-thirds of items are respected in most of the studies. Items such as existence of a protocol and registration, risk of bias in individual studies and across studies, study characteristics, additional analyses and funding are not often mentioned. We suggest that authors of future systematic reviews draw upon the PRISMA checklist to report their methodology and results.

\section{Abbreviations}

ICTs: Information and communication technologies; PRISMA: Preferred reporting items for systematic reviews and meta-analyses; WHO: World Health Organization.

\section{Competing interests}

The authors declare that they have no competing interests.

\section{Authors' contributions}

GM and MPG reviewed abstracts for the umbrella review and drafted the manuscript. GP and JC revised and contributed to the manuscript. All authors read and approved the final manuscript.

\section{Acknowledgements}

We wish to thank Ms Camilia Yousefadeh and Mr Erik Breton for their contribution to this work. This work was part of a project entitled "Supporting work practices through telehealth: impact on nurses in peripheral regions" funded by the Canadian Institutes of Health Research $(\mathrm{CIHR})$, in collaboration with the Ministry of Health and Social Services of Quebec through the program Partnerships for Health System Improvement (Grant \#200911PHE-217,005-PHE-CFBA-111,141). MPG holds the Tier 2 Canada Research Chair on Technologies and Practices in Health, funded by the CIHR and the Canadian Foundation for Innovation.

\section{Author details}

${ }^{1}$ Hôpital St-François d'Assise, Research Center of the Centre Hospitalier Universitaire de Québec, 10 rue de l'Espinay, D6-727, G1L 3L5, Québec, QC, Canada. ${ }^{2}$ Department of Information Technology, 3000, chemin de la Côte-Sainte-Catherine, HEC Montréal, H3T 2A7, Montréal, QC, Canada. ${ }^{3}$ Faculty of Nursing Sciences, Pavillon Marguerite-d'Youville, C.P. 6128 succ. Centre-ville Université de Montréal, H3C 3J7, Montréal, QC, Canada.

Received: 15 March 2013 Accepted: 29 August 2013

Published: 11 September 2013

\section{References}

1. Buchan J, Aiken L: Solving nursing shortages: a common priority. J Clin Nurs 2008, 17:3262-3268.

2. Littlejohn L, Campbell J, Collins-McNeil J: Comparative analysis of nursing shortage. Int J Nurs 2012, 1:22-27.

3. World Health Organization: A Global Survey Monitoring Progress in Nursing and Midwifery. Geneva: WHO; 2010.

4. Law S, Flood C, Gagnon D: Listening for Direction III: National Consultation on Health Services and Policy Issues 2007-2010: Final Report. Ottawa: Canadian 
Health Services Research Foundation and Institute of Health Services and Policy Research, Canadian Institute of Health Research; 2008. http://www. cfhi-fcass.ca/Libraries/Listening_for_Direction/LfDIII-FINAL_ENG.sflb.ashx.

5. Canadian Nurses Association: Tested Solutions For Eliminating Canada's Registered Nurse Shortage. Ottawa: Canadian Nurses Association; 2009. http://www.nursesunions.ca/sites/default/files/rn_shortage_report_e.pdf.

6. Canadian Federation of Nurses Unions: Nursing Workforce Backgrounder. Ottawa: Canadian Federation of Nurses Unions; 2013.

http://www.nursesunions.ca/sites/default/files/2013.backgrounder. nursing workforce.e.pdf.

7. Cho SH, Lee JY, Mark BA, Lee HY: Geographical imbalances: migration patterns of new graduate nurses and factors related to working in non-metropolitan hospitals. J Korean Acad Nurs 2012, 42:1019-1026.

8. Gross JM, Riley PL, Kiriinya R, Rakuom C, Willy R, Kamenju A, Oywer E, Wambua D, Waudo A, Rogers MF: The impact of an emergency hiring plan on the shortage and distribution of nurses in Kenya: the importance of information systems. Bull World Health Organ 2010, 88:824-830

9. Dussault G, Franceschini MC: Not enough there, too many here: understanding geographical imbalances in the distribution of the health workforce. Human Resources Health 2006, 4:12.

10. Dolea C, Stormont L, Braichet JM: Evaluated strategies to increase attraction and retention of health workers in remote and rural areas. Bull World Health Organ 2010, 88:379-385.

11. Henderson LN, Tulloch J: Incentives for retaining and motivating health workers in Pacific and Asian countries. Human Resources for Health 2008, $6: 18$.

12. Serneels $P$, Lindelow M, Montalvo JG, Barr A: For public service or money: understanding geographical imbalances in the health workforce. Health Policy and Planning 2007, 22:128-138.

13. World Health Organization: Increasing Access to Health Workers in Remote and Rural Areas Through Improved Retention. Geneva: WHO; 2010.

14. Mullei K, Mudhune S, Wafula J, Masamo E, English M, Goodman C, Lagarde $M$, Blaauw D: Attracting and retaining health workers in rural areas: investigating nurses' views on rural posts and policy interventions. BMC Health Serv Res 2010, 10(Suppl 1):S1.

15. Molinari DL, Monserud MA: Rural nurse job satisfaction. Rural Remote Health 2008, 8:1055.

16. Lehmann U, Dieleman M, Martineau T: Staffing remote rural areas in middle- and low-income countries: a literature review of attraction and retention. BMC Health Serv Res 2008, 8:19.

17. Williams MA: Rural professional isolation: an integrative review. Online J Rural Nurs Health Care 2012, 12:3-10.

18. Kulig JC, Stewart N, Penz K, Forbes D, Morgan D, Emerson P: Work setting, community attachment, and satisfaction among rural and remote nurses. Public Health Nurs 2009, 26:430-439.

19. Manahan C, Lavoie JG: Who stays in rural nursing practice? An international review of the literature on factors influencing rural nurse retention. Online J Rural Nurs Health Care 2009, 9:82-93.

20. Bambra C, Gibson M, Sowden AJ, Wright K, Whitehead M, Petticrew M Working for health? Evidence from systematic reviews on the effects on health and health inequalities of organisational changes to the psychosocial work environment. Prev Med 2009, 48:454-461.

21. Bialy L, Smith M, Bourke T, Becker L: The Cochrane library and bronchiolitis: an umbrella review. Evidence-Based Child Health: A Cochrane Review Journal 2006, 1:939-947.

22. Egan M, Tannahill C, Petticrew M, Thomas S: Psychosocial risk factors in home and community settings and their associations with population health and health inequalities: a systematic meta-review. BMC Publ Health 2008, 8:239.

23. Liberati A, Altman DG, Tetzlaff J, Mulrow C, Gotzsche PC, loannidis JP, Clarke M, Devereaux PJ, Kleijnen J, Moher D: The PRISMA statement for reporting systematic reviews and meta-analyses of studies that evaluate health care interventions: explanation and elaboration. PLoS Med 2009, 6:e1000100.

24. Bärnighausen T, Bloom DE: Financial incentives for return of service in underserved areas: a systematic review. BMC Health Serv Res 2009, 9:86.

25. Buykx P, Humphreys J, Wakerman J, Pashen D: Systematic review of effective retention incentives for health workers in rural and remote areas: towards evidence-based policy. Aust J Rural Health 2010 18:102-109.
26. Mills JE, Francis $\mathrm{KL}$, Bonner A: Mentoring, clinical supervision and preceptoring: clarifying the conceptual definitions for Australian rural nurses: a review of the literature. Rural Remote Health 2005, 5:410.

27. Gagnon MP, Pollender H, Trepanier A, Duplaa E, Ly BA: Supporting health professionals through information and communication technologies: a systematic review of the effects of information and communication technologies on recruitment and retention. Telemed J E Health 2011, 17:269-274.

28. Fisher KA, Fraser JD: Rural health career pathways: research themes in recruitment and retention. Aust Health Rev 2010, 34:292-296.

29. Stewart BM, Krueger LE: An evolutionary concept analysis of mentoring in nursing. J Prof Nurs 1996, 12:311-321.

30. Lyth GM: Clinical supervision: a concept analysis. J Adv Nurs 2000, 31:722-729.

31. Marrow CE, Hollyoake $K$, Hamer D, Kenrick C: Clinical supervision using video-conferencing technology: a reflective account. J Nurs Manag 2002, 10:275-282.

32. Ohrling K, Hallberg IR: Student nurses' lived experience of preceptorship Part 1-in relation to learning. Int J Nurs Stud 2000, 37:13-23.

33. Ryan-Nicholls KD: Preceptor recruitment and retention. Can Nurse 2004, 100:18-22.

34. Sargeant J, Allen M, Langille D: Physician perceptions of the effect of telemedicine on rural retention and recruitment. J Telemed Telecare 2004, 10:89-93.

35. Pennsylvania Homecare Association (PHA): 2003-2004: telehealth project evaluation: year two: the impact of telehealth on nursing workload and retention. Research report. Pennsylvania Homecare Association; 2004.

36. Eley RM, Hindmarsh N, Buikstra E: Informing rural and remote students about careers in health: the effect of health careers workshops on course selection. Aust J Rural Health 2007, 15:59-64.

37. Somers GT, Strasser R, Jolly B: What does it take? The influence of rural upbringing and sense of rural background on medical students' intention to work in a rural environment. Rural Remote Health 2007, 7:706.

38. Goudy WJ: Community attachment in a rural region. Rural Social 1990, 55:178-198

39. Rabinowitz HK, Diamond JJ, Markham FW, Paynter NP: Critical factors for designing programs to increase the supply and retention of rural primary care physicians. JAMA 2001, 286:1041-1048

40. Smith R, Pilling S: Supporting the transition from student to professional - a case study in allied health. Aust health Rev 2008, 32:134-138.

41. MacLeod ML, Kulig JC, Stewart NJ, Pitblado JR, Knock M: The nature of nursing practice in rural and remote Canada. Can Nurse 2004, 100:27-31.

doi:10.1186/1478-4491-11-44

Cite this article as: Mbemba et al:: Interventions for supporting nurse retention in rural and remote areas: an umbrella review. Human Resources for Health 2013 11:44

\section{Submit your next manuscript to BioMed Central and take full advantage of:}

- Convenient online submission

- Thorough peer review

- No space constraints or color figure charges

- Immediate publication on acceptance

- Inclusion in PubMed, CAS, Scopus and Google Scholar

- Research which is freely available for redistribution 